\title{
Empirical Evidence on the Preferences of Racetrack Bettors
}

\author{
Bruno Jullien* $\quad$ Bernard Salanié ${ }^{\dagger}$
}

May 2005.

Forthcoming chapter in Efficiency of Sports and Lottery Markets, Handbook in Finance series, D. Hausch and W. Ziemba eds.

\section{Introduction}

This chapter is devoted to the empirical estimation of the preferences for risk of gamblers on real market data. While there have been several experimental studies trying to elicit preferences of gamblers in the laboratory ${ }^{1}$, the observation of real markets remains a necessary step in assessing the properties of gamblers' preferences. $^{2}$ This is particularly true for gambling; it is indeed often asserted that gambling on race tracks (or in a casino) involves some type of utility that is hardly replicable in experiments ${ }^{3}$.

We concentrate in this survey on the empirical work that has been conducted for horse races ${ }^{4}$, in the pari-mutuel system or in a bookmaker system ${ }^{5}$. Horse race markets (or other types of betting markets, such as sport events for instance) are very good natural experiment candidates to test theories of preferences under risk: they allow to collect large datasets, and the average amount of money at stake is significant ${ }^{6}$. Financial markets would be a natural area where the empirical relevance of the implications of the various non expected utility models could be tested. ${ }^{7}$ However, portfolio choices have a very marked

*University of Toulouse (IDEI and GREMAQ (CNRS)). Email: bjullien@cict.fr

${ }^{\dagger}$ Columbia University and CREST. Email: bs2237@columbia.edu

${ }^{1}$ See the survey by Camerer (1995).

${ }^{2}$ An alternative is to use household surveys (see for instance Donkers et al (2001)).

${ }^{3}$ See for instance Thaler and Ziemba (1988).

${ }^{4}$ There has been some work on Lotto games, sport events and TV shows (see the conclusion).

${ }^{5}$ For interested readers, Haush, Lo and Ziemba (1994) present contributions covering most aspects of the economics of racetrack betting.

${ }^{6}$ Weitzman (1965) estimates an average 1960's $\$ 5$ win bet on individual horses, while Metzger (1985) evaluates at $\$ 150$ the average amount bet by an individual during the day in 1980.

${ }^{7}$ For a recent overlook at the theory and empirics of portfolio choices, see the contributions in Guiso, Haliassos and Jappelli (2002). 
dynamic character, and non expected utility theories are difficult to handle in dynamic settings.

Racetrack studies may provide key insights for the analysis of risk taking behavior in financial investment, as well as in other contexts where risk is a main issue (environmental risk for instance). Betting markets have the advantage of being short-run, lasting for one period only. This allows an exact evaluation of the ex-post return on each bet. As such they provide an "archetype" of a simple contingent security market as defined by Arrow (1964). For horse races, a winning bet of 1 dollar on a particular horse is simply a contingent security that yields a revenue $(R+1)$ dollars in the event the horse wins the race and 0 otherwise. Note that such a security cannot be retraded. The odds $R$ of the horse in this context is defined as the net return in the winning case ${ }^{8}$. In a bookmaker system, odds are commitments of payment by bookmakers who quote the prices. In a pari-mutual system, they are endogenous, resulting from the distribution of the wagers over the horses: the odds of horse $i$ is the ratio between the total money $B$ wagered on the race net of the track revenue ${ }^{9}$ and the total money wagered on the horse $B_{i}$, minus 1 :

$$
R_{i}=\frac{(1-t) B}{B_{i}}-1 \text {, where } t \text { is the take. }
$$

At any point in time, odds reflect the market information on winning probabilities and evolve over time, until the race starts. In particular data may include odds quoted before the racetrack opens, and odds quoted on the track. The most common practice is to use starting prices, that is odds measured at the last minute of betting ${ }^{10}$. The empirical studies discussed below then start with odds data and winners data, and use them to derive econometric estimates of bettors preferences.

Note that there is clearly a selection bias in focusing on bettors and starting prices. Not all individuals bet, and the population of individuals betting on track (and thus going to the race field) is hardly representative of the whole population. It may even not be representative of the whole population of bettors, as bettors off-track are not the same as bettors on-track. So the only information that can be derived is information on the preferences exhibited by individuals betting on the fields. Still, this is informative on the type of risk that individuals may endorse, and, given the simple nature of the market, this provides a very good test for various theories of preference under risk. Moreover as the selection bias is in the direction of selecting individuals within the most risk loving part

\footnotetext{
${ }^{8}$ A 3 to 1 odd thus correspond to a $R=3$ and thus a gain of $\$ 4$ for a bet of $\$ 1$ in the event that the horse wins the race. Following the empirical literature we focus on win bets, and ignore combinatorial bets.

${ }^{9}$ It includes the take and the breakage. The take corresponds to the percentage of bets collected by the racetrack organizers, and the taxes. The breakage corresponds to the part of the return lost due to the fact that it is rounded to the nearest monetary unit.

${ }^{10}$ The studies discussed below could be done with any odds, under a rational expectation assumption. The informational content of prices is the highest at starting prices, so that they should provide a more accurate predictor of winning probabilities than earlier odds. See for instance Asch et al (1982).
} 
of the population, this provides an over-estimate of (and thus a bound on) the level of risk that an average individual may be willing to accept, which is clearly very useful.

Using econometric methods on race track data has the advantage of exploiting the large size of the samples available. Datasets usually include thousands of races, and thus allow precise estimates. Moreover, it enables to rely on fairly standard econometric models and procedures, ranging from the simple regression methods used in early work, to more sophisticated estimations of structural models. The main drawback is that individual data on bets and on bettors characteristics are not available. This implies several restrictions. First, the size of the wager can usually not be identified. Second, going to the race track and betting involves some type of entertainment value, and it is not possible to disentangle what is due to the specific utility derived from the attendance to the race, and more fundamental properties of preferences. It is also clear that racetrack bettors have heterogeneous preferences and information. Such a heterogeneity could be captured with a parametric estimation of the underlying distribution of bettors' characteristics (preferences and beliefs), although this would raise serious identification problems. The lack of individual data has led researchers to focus on some form of average behavior, or more to the point on the behavior of a "representative" bettor that captures the average risk attitude imbedded in the dataset.

In what follows we first present (Section 2) the main stylized facts of horse races that have shaped the research agenda. We then present in Section 3 the work based on the expected utility model, which put in place the foundations for subsequent work. Section 4 and 5 then review the work departing from the expected utility paradigm. Section 4 focuses on the perception on winning probabilities by bettors, while Section 5 discusses the role of the reference point and the asymmetric treatment of wins and losses. Section 6 concludes.

\section{Some Stylized Facts}

Any empirical study of the preferences of racetrack bettors must account for the most salient stylized fact of racetrack betting data: the favorite-longshot bias. The favorite-longshot bias refers to the observation that bettors tend to underbet on favorites and to overbet on outsiders (called longshots). As it is presented in more detail by Hodges and Ziemba in this Handbook, we only recall here the points that matter for our discussion ${ }^{11}$. Thus we focus on the implications of the favorite-longshot bias on how we view bettors' preferences.

The favorite-longshot bias seems to have been documented first by Griffith (1949) and McGlothlin (1959). Griffith studied 1,386 races run under the pari-mutuel system in the United States in 1947. For each odds class $R$, he computed both the number of entries $E_{R}$ (the total number of horses with odds in odd class $R$ entered in all races) and the product of the number of winners

${ }^{11}$ See also Haush, Lo and Ziemba (1994) for a survey of the evidence. 
in this class and the odds $N_{R}$. A plot of $E_{R}$ and $N_{R}$ against $R$ showed that while the two curves are very similar, $N_{R}$ lies above (resp. below) $E_{R}$ when $R$ is small (resp. large). Since small $R$ corresponds to short odds (favorites) and large $R$ to long odds (longshots), this is evidence that in Griffith's words, there is "a systematic undervaluation of the chances of short-odded horses and overvaluation of those of long-odded horses". A risk-neutral bettor with rational expectations should bet all his money on favorites and none on longshots.

A number of papers have corroborated Griffith's evidence on the favoritelongshot bias ${ }^{12}$. To give just one example, let us look at the dataset used by Jullien-Salanié (2000). This dataset comprises each flat horse race run in Britain between 1986 and 1995, or 34,443 in total. British race track betting runs on the bookmaker system, so odds $R$ are contractual. This dataset makes it easy to compute the expected return of betting on a horse with given odds, as plotted in Figure 1. For any given $R$, we compute $\hat{p}(R)$, the proportion of horses with rate of return $R$ that won their race. The expected return then is

$$
\widehat{E R}(R)=\hat{p}(R) R-(1-\hat{p}(R))
$$

for a bet of $£ 1$, since such a bet brings a net return of $R$ with probability $\hat{p}(R)$ and a net return of -1 with probability $(1-\hat{p}(R))$.

Figure 1 plots $\widehat{E R}(R)$, along with a $95 \%$ confidence interval. The expected return is always negative (the occasional spikes on the left of the figure are for odds that correspond to relatively few horses): it does not pay for a risk-neutral bettor to gamble at the racetrack. More interestingly, the expected return decreases monotonically with the odds $R$, so that it is much less profitable for such a bettor to bet on longshots than to bet on favorites: even for very common odds of 10 to 1 , the expected loss is 25 pence on the pound, as compared to less than 10 pence for horses with even odds (of 1 to 1 ).

The favorite-longshot bias has been much discussed and four main types of explanations have emerged in the literature ${ }^{13}$ :

1. The original explanation of the favorite-longshot bias was given by Griffith (1949) and referred to misperceptions of probabilities by bettors. Griffith argued that as in some psychological experiments, subjects tend to underevaluate large probabilities and to overevaluate small probabilities. Thus they scale down the probability of a favorite winning a race and they scale up the probability that a longshot wins a race, which indeed generates the favorite-longshot bias. Henery (1985) suggests a somewhat similar explanation. He argues that bettors tend to discount losses: if the true probability that a horse loses the race is $q$, they take it to be $Q=f q$, where $0<f<1$ is some constant number. This theory can be tested by

\footnotetext{
${ }^{12}$ Exceptions have been found for Hong Kong races by Bushe and Hall (1988).

${ }^{13}$ Ali (1977) also points that the favourite-longshot bias can be explained by heterogeneous beliefs, reflecting different subjective probabilities of bettors and a lack of common knowledge. We skip this explanation here. This would amount to introduce some heterogeneity in nonexpected utility modles with probability distortions, and so far, the data set has not allowed to account for such heterogeneity.
} 


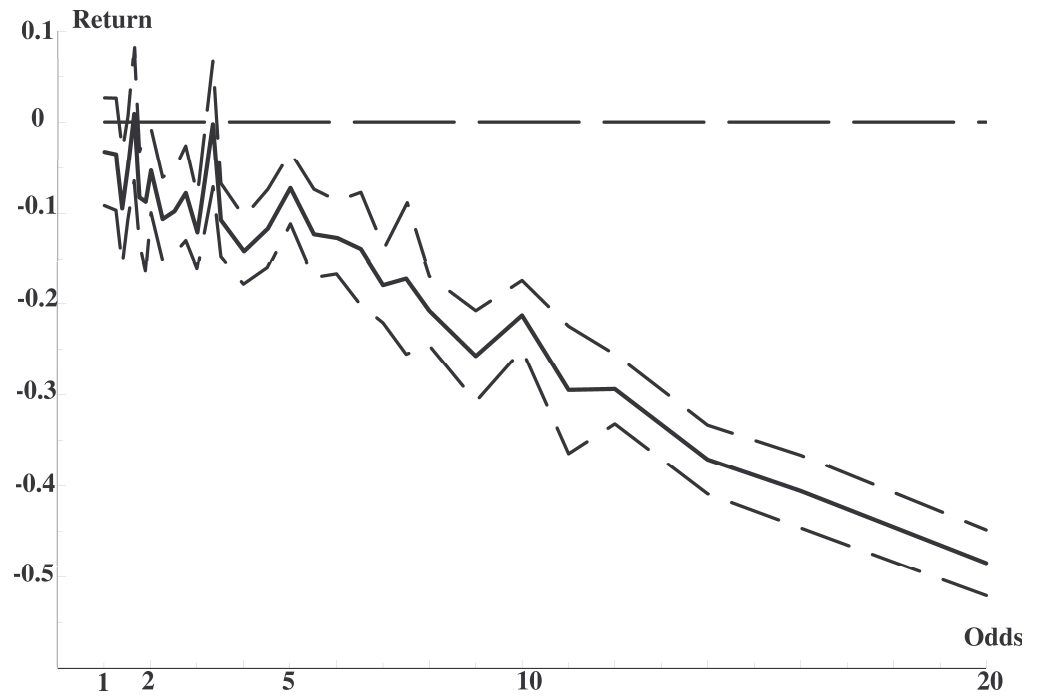

Figure 1: Observed Expected Return 
measuring $Q(R)$ to be the value that makes the expected return of betting on a horse with odds $R$ exactly zero; from the formula above, this $Q(R)$ equals $R /(R+1)$. Now the value of $q(R)$ is given as $q(R)=1-\hat{p}(R)$. By regressing $Q(R)$ on $q(R)$ without a constant, Henery found an estimated $f$ of about 0.975 and a rather good fit ${ }^{14}$.

2. Quandt (1986) showed how risk-loving attitudes generate the favoritelongshot bias at the equilibrium of betting markets. To see this, take two horses $i$ and $j$ in the same race, with odds $R_{i}$ and $R_{j}$ and true probabilities of winning $p_{i}$ and $p_{j}$. The expected return of betting one dollar on horse $h=i, j$ is

$$
\mu_{h}=p_{h} R_{h}-\left(1-p_{h}\right)
$$

and the variance of this bet is

$$
v_{h}=p_{h} R_{h}^{2}+\left(1-p_{h}\right)-\mu_{h}^{2}
$$

which is easily seen to be

$$
v_{h}=p_{h}\left(1-p_{h}\right)\left(R_{h}+1\right)^{2}
$$

Now if bettors are risk-loving, the mean-variance frontier must be decreasing in equilibrium: if $\mu_{i}<\mu_{j}$, then it must be that $v_{i}>v_{j}$. A fortiori equilibrium requires that

$$
\frac{v_{i}}{\left(\mu_{i}+1\right)^{2}}>\frac{v_{j}}{\left(\mu_{j}+1\right)^{2}}
$$

But easy computations show that

$$
\frac{v_{h}}{\left(\mu_{h}+1\right)^{2}}=\frac{1-p_{h}}{p_{h}}
$$

so that if $\mu_{i}<\mu_{j}$, then $p_{i}<p_{j}$. The contrapositive implies that horses with a larger probability of winning (favorites) yield a higher expected return, which is exactly the favorite-longshot bias.

3. Following evidence of informed trading (Ash et al (19982), Craft (1985)), Shin showed in a series of papers $(1991,1992,1993)$ that in a bookmakers' market, the presence of insider traders generates the favorite-longshot bias as bookmakers set odds so as to protect themselves against such wellinformed bettors.

4. Finally, it may be that the utility of gambling is higher for bets on longshots, perhaps because they provide more excitement; this explanation is advanced by Thaler and Ziemba (1988). Then if risk-neutral bettors equalize the sum of the expected return and the utility of gambling across horses in each race, clearly the expected return will be higher for favorites.

\footnotetext{
${ }^{14}$ Although our own estimates on our dataset suggest that the constant term in $Q=a+b q$ is highly significant.
} 
These four explanations are not mutually incompatible. In modern terms that were not available to Griffith (1949), explanation 1 hints to a non expectedutility model of bettors' preferences with nonlinear weighing of probabilities. ${ }^{15}$ Explanation 2 therefore can be subsumed in explanation 1, with risk-loving appropriately redefined so that it makes sense for non expected-utility preferences.

Because the rest of this chapter will focus on explanations 1 and 2, we should explain here why we put aside explanations 3 and 4 . The literature on, inside trading is covered in Sauer (1998) along with the test of efficiency of wagering markets. For our concern, one first problem with Shin's models is that they are rather specific, so that estimating the incidence of insider trading requires strong assumptions on preferences and the information structure of insider traders. Still, it might make sense to pursue along this direction. However, this is in fact not necessary so far as the gambler's preference is the object of interest. It is true that the existence of a fringe of insider traders changes the behavior of bookmakers; but under rational expectations, all the information available is incorporated into prices so that one may still estimate the preferences of a gambler with no private information. Finally, explanation 4 also is intuitively appealing: betting on a huge favorite, say with a $99 \%$ chance of making a net return of 1 cent on the dollar, is clearly less "fun" than betting on a longshot that brings 100 dollars with a $1 \%$ probability. One difficulty with this explanation is that in a sense, it explains too much: since there is little evidence on the determinants and the functional form of the utility of gambling, any feature of the equilibrium relationship between $p$ and $R$ can be explained by an ad hoc choice of functional form for the utility of gambling. However, we will see later that models with non expected-utility preferences, by re-weighting probabilities, may yield similar predictions to models with a utility of gambling that depends on the probability of a win.

\section{$3 \quad$ Expected Utility}

The seminal contribution in the domain is the work of Weitzman (1965) who builds on the above findings and attempts to estimate the utility function of an average expected utility maximizer. Weitzman had at his disposal a dataset of 12,000 races, collected on four New York race tracks for a period covering 1954 to 1963. Following Griffith (1949), Wietzman starts by aggregating horses over all races by odds category, obtaining 257 odds classes. From the winners dataset, he then constructs the ex-post estimate $\hat{p}(R)$ of the winning probability of a horse conditional on its odds category $R$. This allows him to estimate a functional relation between the odds category and the winning probability. ${ }^{16}$ Then he attempts do build the utility function of an "average" bettor, referred to as Mr. Avmart (average man at the race track), as follows. Mr. Avmart is an expected utility maximizer with a utility function $u($.$) and he bets a fixed amount on each$

\footnotetext{
${ }^{15}$ See the conclusion for other types of cognitive biases.

${ }^{16} \mathrm{He}$ estimates an hyperbola $\hat{p}(R)=\frac{0.845}{R}$ and a "corrected hyperbola" $\hat{p}(R)=$ $\frac{1,01-0.09 \log (1+R)}{R}$.
} 
race, ${ }^{17}$ normalized to 1 for the exposition (the actual unit Weitzman uses is $\$ 5$ ). Mr. Avmart is representative in the following sense: the data observed could be generated by Mr. Avmart (or a population of identical Mr. Avmarts) betting. As every odds category receives some bet, Mr. Avmart must be indifferent between all the odds categories, which implies that

$$
\hat{p}(R) u(R)+(1-\hat{p}(R)) u(-1)=K \text { for all } R,
$$

where $K$ is the constant expected utility. This yields the relation

$$
u(R)=u(-1)+\frac{K-u(-1)}{\hat{p}(R)},
$$

which allows him to estimate a utility function for all money levels $R$. Using this procedure Weitzman found a convex utility function on the range of money value covered ( $\$ 5$ to $\$ 500)$, consistent with the assumption of a risk-loving attitude.

Ali (1977) conducted a similar study with a 20,247 races dataset, grouping the horses according to their ranking as opposed as their odds. For each ranking an average odds and an empirical winning probability are computed. He then estimates the utility function of an agent indifferent between betting on any horse category. Ali confirms Weitzman finding, with a risk loving utility function. He estimates a constant relative risk aversion utility (CRRA) with a coefficient of relative risk aversion -0.1784. Applying the methodology on different data, Kanto et al (1992) and Golek and Tamarkin ((1998) estimate somewhat similar CRRA utility functions. ${ }^{18}$

By construction, the preferences of the representative agent are based only on the information contained in the odds category (or the ranking in the case of Ali). The behavior of the agent is "representative" on average, in the sense that he is indifferent between betting on the horse in a given category on all races, and betting on the horse in another category on all races. ${ }^{19}$ Thus the construction of Mr Avmart's preferences involves two types of aggregation: of the information over odds and winning probabilities, and of the preferences. One of the drawbacks of the categorization of odds is that the number of points used to fit the utility function is usually small (except for Weitzman (1965) who builds 257 categories). Another important aspect is that the only information used is the category of the horse, so some information on the races included in the data is not used by Mr Avmart. This is the case for instance of the number of runners in each race. Given the nature of the pari-mutual system, one may however think that the number of runners may affect the relationships between the winning probability and the odds. More generally, this relationship may

\footnotetext{
${ }^{17}$ Recall that data on individual bets are not available, so the amount bet must be postulated.

${ }^{18}$ Golek and Tamarkin's estimates, based on odds category, are -0.14 for the whole data, and -0.2 for a data conditioned on having a large favorite. Values differ but they all confirm a risk-loving attitude.

${ }^{19} \mathrm{Or}$ in a race chosen at random in the sample of races.
} 
vary with the race characteristics. ${ }^{20} \mathrm{~A}$ second remark is that it may also vary with the take, or more generally with the mark-up over winning probabilities that corresponds to the revenue of the betting institution. In the case of a parimutual market this is not so problematic as the take is fixed at the track race level. But, when applied to a betting market organized with bookmakers, the procedure may create serious biases as the mark-up is chosen by the bookmakers and may vary from one race to the another. ${ }^{21}$.

Jullien and Salanié (2000) propose a method to estimate the representative agent's preferences that allows to account for heterogeneity among races. To understand the procedure, let us consider a given race $r$ with $E_{r}$ horses. Let $p_{i r}$ denote the objective winning probability of horse $i$ in race $r$ and $R_{i r}$ be the odds. Now assume that the representative agent is indifferent between betting 1 on any horse in race $r$. Then there must be some constant $K_{r}$ such that:

$$
p_{i r} u\left(R_{i r}\right)+\left(1-p_{i r}\right) u(-1)=K_{r} .
$$

Using the fact that probabilities add up to one, one can then recover for each race and each horse, a unique predicted probability of winning $\hat{p}(i, r, u)$ and a constant $K_{r}$ consistent with this relation. The procedure consists then in using the winners data to find the utility function $u($.$) that provides the best$ fit to the empirical data using a maximum likelihood method. Note that the method has the advantage of using all the data information, and getting rid of the categorization of odds. The nature of the representative agent is slightly different as he is indifferent between betting on any horse on any given race, as opposed to placing a systematic bet on a given odds category on all races. Thus the agent too uses all the information in the data, and may even use more information as he can adjust to the specificities of races.

Applying this procedure to the estimate of a utility function, Jullien and Salanié confirmed the finding of a risk loving utility function. It appears however that the $C R R A$ utility representation is outperformed by a utility function with a constant absolute risk aversion $(C A R A)$. Among the class of utility functions with an hyperbolic risk aversion, the best fit was obtained for a $C A R A$ utility function, with a fairly moderate degree of risk-loving.

Expected utility estimates provide results that are consistent with explanation 2 of the favorite-longshot bias, that is a risk-loving attitude. However, as documented by Golek and Tamarkin (1998), and Jullien and Salanié (2000), these estimates tend to perform poorly for large favorites. Indeed the probabilities of winning implied by the estimated utility and the underlying structural model of representative agent tend to be too small for large favorites. Arguably this can be due to the parametric forms chosen for the utility function estimated, which restrict its curvature. Arguing that CRRA utility functions

\footnotetext{
${ }^{20}$ McGlothin (1956) and Metzger (1985) provide evidence that the position of the race in the day matters, as well as the amount of publicity for the race.

${ }^{21}$ If the average mark-up varies with the race, as it is the case with bookmakers, the constant $K$ above should depend on the race. The same issue arises when using data from racetracks with different values of the take.
} 
perform poorly for large favorites, Golek and Tamarkin (1998) estimate a cubic utility function: $u(R)=-0.071+0.076 R-0.004 R^{2}+0.0002 R^{3}$. The utility function exhibits risk aversion for low odds (favorites) and a risk loving attitude for larger levels of odds. As the coefficient for the variance is negative, they conclude that the risk loving attitude is related to the skewness of the distribution (the third moment). While the risk averse attitude for small probabilities is an interesting result, this is probably as far as one can go with the expected utility model on this type of dataset. In particular, given the specific economic context, the non representativeness of the population studied and the lack of data on individual bets and characteristics, very detailed estimates of the curvature of the utility function at various levels of odds may not be of much relevance for other applications. We now follow a different route. As argued before, although the precise preference of racetrack bettors may not be of special interest to the economist in a different domain, they provide a simple and clear real life experiment. The next step is thus to use the data to test various departures from the expected utility paradigm on a real life situation. Among these, the most popular in modern theory are the so-called non-expected utility models which provide mathematical representations of preferences under risk that are non-linear in the space of probability distributions.

Before we procees, let us point out that there is no inherent contradiction between the expected utility representation and a non-expected utility model of the agent behavior. Indeed, as we already noted, the data contains no information on the individual characteristics, and in particular on wealth. This means that all the utility functions are estimated only for the revenue derived from the betting activity. One may then consider that the distribution of this revenue represents a relatively small fraction of the risk supported by individuals on their total wealth, at least for the average bettor. As shown by Machina (1982), even when an agent evaluates his total wealth in a non-expected utility manner, one may still evaluate small risks with an expected utility. The utility function is then local as it represents the differential of the global functional, and it depends on the underlying total wealth. Thus one may see expected utility estimates as a first order linear approximations of preferences. The question is then whether alternative utility representations provide a better representation of preferences than this approximation.

\section{Distortions of Probabilities}

The empirical evidence collected in the previous section suggests that the best expected utility rationalization of the equilibrium relationship between probabilities and odds exhibits a significant but not very large degree of risk loving. Still, a very copious experimental literature, starting with the work of Allais (1953), has accumulated to shed doubt on the value of the expected utility model as a representation of behavior under risk. The recent survey by Camerer (1995) for instance strongly suggests that the independence axiom is violated in most experiments. 
On the other hand, there is no consensus about which non expected utility model to choose, even among authors who hold that we should drop the expected utility representation. Moreover, most of the evidence is experimental; there seems to be little evidence based on real-life economic situations. As argued in the introduction, bets on horses are very simple Arrow-Debreu assets that cannot be retraded and thus offer an exciting way of testing these theories. This section and the next are dedicated to this task. As it will appear, most of these two sections describes the study of Jullien and Salanié (2000). We can only hope that in ten years, there will be many more papers to present in this field.

Let us stick to the assumption that the utility of wealth $u$ function is CARA; then the expected utility of betting on horse $i$ with odds $R_{i}$ and probability of winning $p_{i}$ is

$$
p_{i} u\left(R_{i}\right)+\left(1-p_{i}\right) u(-1)
$$

This is a special case of the standard formula

$$
\int u(x) d F(x)
$$

where the risky outcome $X$ has a cumulative distribution function $F$. There are many ways of altering this formula in order to obtain a non expected utility representation of preferences. One of the most natural, suggested by Quiggin (1982), consists in re-weighting probabilities, so that the value of $X$ now takes the form

$$
-\int u(x) d(G \circ(1-F))(x)
$$

where $G$ is a continuous and increasing function that maps $[0,1]$ into itself. While this may seem opaque, the application of this formula to the bet on horse $i$ yields

$$
G\left(p_{i}\right) u\left(R_{i}\right)+\left(1-G\left(p_{i}\right)\right) u(-1)
$$

While Quiggin (1982) called this specification "anticipated utility", it now goes under the name of "rank dependent expected utility" (RDEU for short). Because $G$ is a priori nonlinear, RDEU breaks the independence axiom of expected utility. It does so in ways that may allow it to account for violations such as the Allais paradox: when $G$ is convex, RDEU preferences indeed solve what is called in the literature the "generalized Allais paradox".

Remember that Griffith (1949) explained the favorite-longshot bias by appealing to an overestimation of small probabilities and an underestimation of large probabilities. This points to a $G$ function that is concave and then convex. On the other hand, the weighting function postulated by Henery (1985) does not fit within RDEU, strictly speaking. It can indeed be written as

$$
G(p)=1-f(1-p)
$$

which gives $G(0)=1-f>0$ and thus is inconsistent with the axioms of RDEU (and indeed of any reasonable theory of choice under risk). This could of course be fixed by smoothly connecting $G(0)=0$ with the segment represented by 
Henery's specification. Note that neither of these specifications yields a convex weighting function $G(p)$, as required to solve the generalized Allais paradox.

Jullien and Salanié (2000) fitted various RDEU functionals to their dataset of British flat races. All of these functionals assumed that the utility of wealth function $u$ was a CARA function; on the other hand, they allowed for much more flexibility on the shape of the weighting function $G(p)$, which allowed them to nest the shapes suggested by Henery and Griffith among others. Figure 2 offers a summary of their results. The most striking feature of these curves is that they are very close to the diagonal for each specification. Thus the estimated RDEU functionals hardly depart from the expected utility model. This is confirmed by formal tests, since the null hypothesis of expected utility is only rejected for one specification of the weighting function, that proposed by Prelec (1998) on the basis of an axiomatic derivation. According to this study at least, rankdependent expected utility does not appear to provide a better fit of bettors' preferences than expected utility. Note that if anything, the estimated weighting functions are slightly convex on the whole $[0,1]$ interval and thus do not go in the direction suggested by Griffith or Henery.

\section{Reference Points and Asymmetric Probability Weights}

While the results in the previous section are not very encouraging for non expected utility, there are many alternative specifications of these models. In particular, since Markowitz (1952), the notion of reference point has received some attention. This refers to the idea that individuals evaluate the risk by comparison to some reference wealth, and treat losses and gains in an asymmetric way. This is particularly attractive in the case of betting as there is a natural reference point (no bet) and a clear distinction between losses and gains.

In a recent work, Bradley (2003) proposes such a representation where the agent maximizes an expected utility with a reference point and a differential treatment of losses and gains. ${ }^{22}$ His representation assumes a different constant relative risk aversion utility function for losses and for gains, and allows to endogeneize the size of the bet, which is not done in other approaches. Although his investigation is still preliminary, it suggests that a representation with risk aversion on losses and a risk loving attitude on gains may fit the data, in particular the favorite-longshot bias.

Among various theories involving a reference point, cumulative prospective theory (CPT) has become very popular in recent years. Prospect theory was introduced by Kahneman and Tversky (1979) and developed into cumulative prospect theory in Tversky and Kahneman (1992). Most theories of choice under risk evaluate lotteries as probability distributions over final wealth. CPT diverges from this literature in that it evaluates changes in wealth with respect

\footnotetext{
${ }^{22}$ As pointed in section 2 , if we see the utility function as a local utility function, the notion of reference point becomes natural.
} 


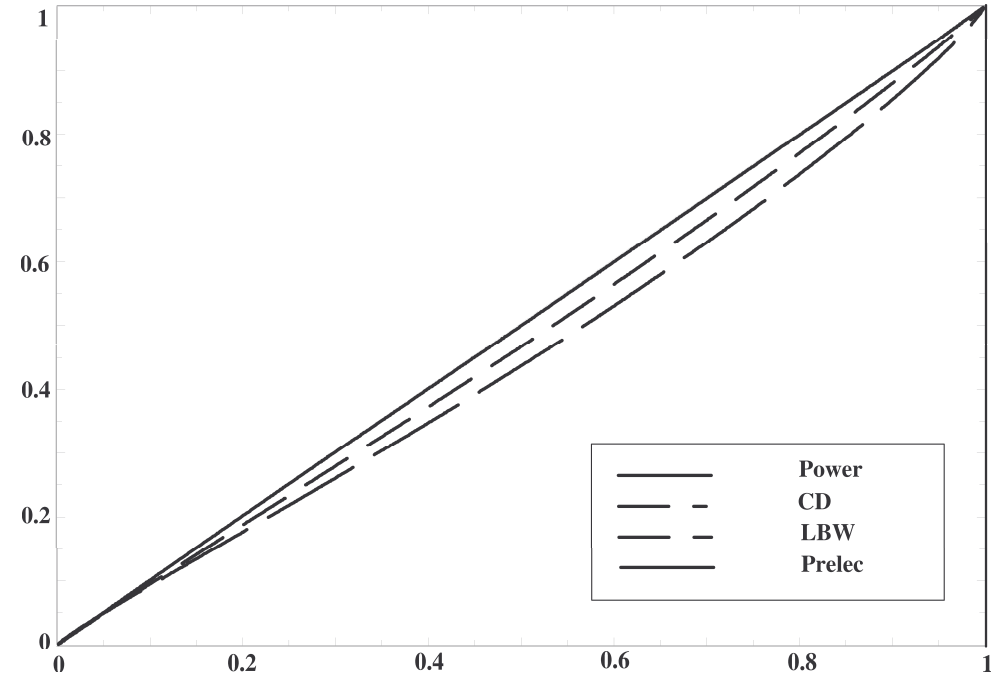

Figure 2: Estimated Weighting Functions for RDEU 
to a reference point that may for instance be current wealth. This matters in that in CPT, losses and gains are evaluated in different ways. Kahneman and Tversky first appeal to the principle of diminishing sensitivity, which states that the psychological impact of a marginal change decreases when moving away from the reference point. Applied to the utility of (changes in) wealth function, it suggests that this function is concave for gains but convex for losses. When applied to the probability weighting function, and given that the endpoints of the $[0,1]$ interval are natural reference points, it suggests that this function should have the inverted-S shape implicit in Griffith (1949), as shown in figure ??. This is often called the certainty effect: small changes from certain

Cumulative prospect theory also adds two elements of asymmetry in the treatment of gains and losses. First, it allows for different probability weighting functions for gains and losses. Second, it assumes loss aversion, i.e. that the utility of changes in wealth is steeper for losses than for gains, so that the function $u(x)$ has a kink in zero.

For a general prospect $X$ with cumulative distribution function $F$, the value according to $\mathrm{CPT}$ is

$$
\int_{x<0} u(x) d(H \circ F)(x)-\int_{x>0} u(x) d(G \circ(1-F))(x)
$$

where $G$ and $H$ are two continuous and increasing functions that map $[0,1]$ into itself. Given a bet on horse $i$ with odds $R_{i}$ and a probability of a win $p_{i}$, the CPT value simplifies into

$$
\left.G\left(p_{i}\right) u\left(R_{i}\right)+H\left(1-p_{i}\right)\right) u(-1)
$$

Note the differences with RDEU. The most obvious one is that in general $H(1-$ $p) \neq 1-G(p)$. The other one is hidden in the formula, since the function $u$ should have a shape similar to that in figure ??: it should be convex for losses $(x<0)$, have a "concave kink" in zero (with $u(0)=0$ ), and be concave for gains $(x>0)$. Clearly, only some of these properties can be tested from the data, since the only values of $u$ on which we can recover information are those in -1 and on $[\underline{R},+\infty)$, where $\underline{R}$ is the smallest odd observed in the data.

In their paper, Jullien and Salanié (2000) chose to circumvent these difficulties by assuming that $u$ was a CARA function. This is clearly not satisfactory, as it assumes away by construction any form of loss aversion and it violates the principle of diminishing sensitivity by forcing the concavity of $u$ to have the same sign for losses and for gains. Jullien and Salanié normalize $u$ by setting $u(0)=0$ and $u^{\prime}(0)=1$; then the parameter of the CARA function is estimated from the relationship between probabilities and odds, and it implies a value for $u(-1)$, say $A$. Then they run a test of (and do not reject) the null hypothesis that $u(-1)=A$. This may be construed as a test of loss aversion by a sympathetic reader, but we admit that it is not very convincing. The best justification for their assuming a CARA utility function probably is that they want to focus on the probability weighting functions $G$ and $H$ and there is just not enough information in the data to probe more deeply into the function $u$. 


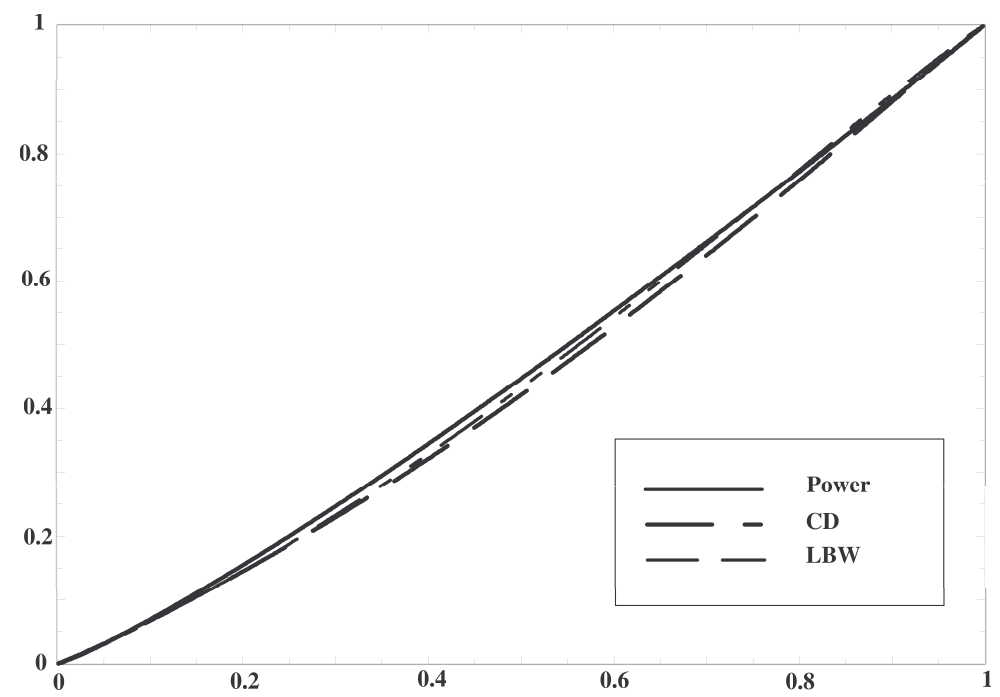

Figure 3: CPT Probability Weighting for Gains 


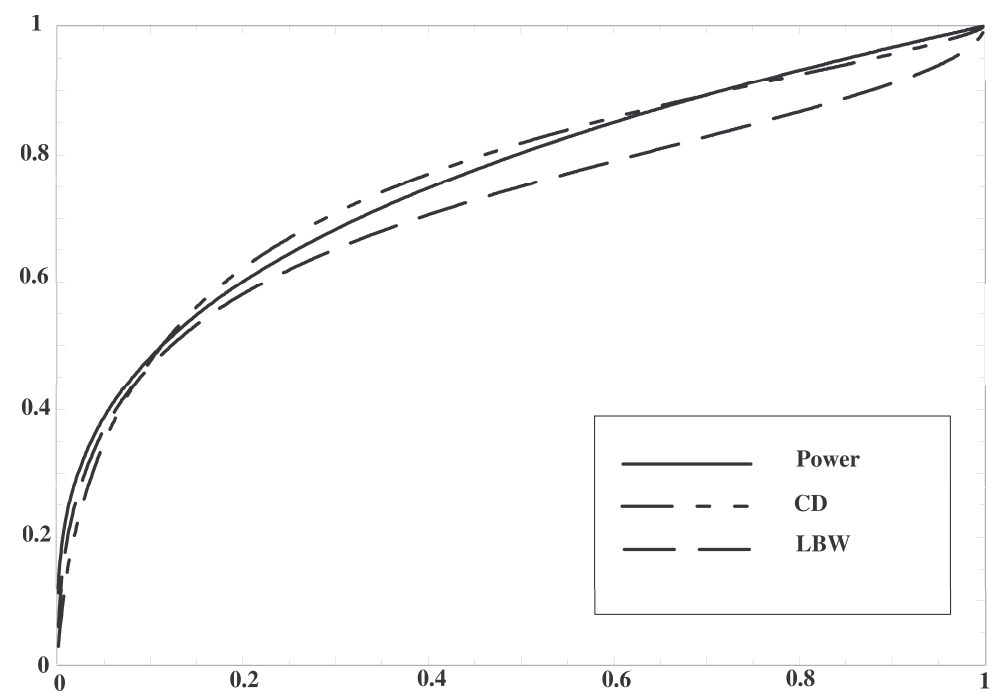

Figure 4: CPT Probability Weighting for Losses 
Given this restriction, Jullien and Salanié tried three specifications for the functions $G$ and $H$. Figure 3 plots their estimation results for the function $G$. As in the RDEU case, the function appears to be slightly convex but very close to the diagonal: there is little evidence of a distortion of the probabilities of gains. The estimated $H$ function, however, has a markedly concave shape for all specifications as shown in figure 4 . These results are somewhat at variance with the theory, which led us to expect inverted-S shapes for the probability weighting functions.

There are several ways to interpret these results, and Jullien and Salanié illustrate some of them. First, it can be shown that $G$ convex and $H$ concave explain the generalized Allais paradox. Second, local utility functions à la Machina (1982) can be derived from these estimates; they have a shape similar to that hypothesized by Friedman and Savage (1948). Let us focus here on how these preferences explain the favorite longshot-bias. To see this, remember that the function $u$ exhibits a moderate degree of risk-loving, and the function $G$ is very close to the diagonal. Thus to simplify things, assume $u(x)=x$ and $G(p)=p$. Then horse $i$ is valued at

$$
p_{i} R_{i}-H\left(1-p_{i}\right)
$$

which can be rewritten as

$$
p_{i}\left(R_{i}+1\right)-1-\left(H\left(1-p_{i}\right)-\left(1-p_{i}\right)\right)
$$

Now given the estimates of Jullien and Salanié, the function $q \longrightarrow H(q)-q$ is zero in 0 and 1 and has a unique maximum close to $q^{*}=0.2$. Since most horses have a probability of winning much lower than $1-q^{*}=0.8$, it follows that $H(1-p)-(1-p)$ is an increasing function of $p$ and therefore in equilibrium, the expected return $p_{i}\left(R_{i}+1\right)-1$ is an increasing function of the probability of a win. Thus bigger favorites are more profitable bets for risk-neutral bettors, which is just the definition of the favorite-longshot bias. The data suggest that the bias may be due not only to risk-loving, as suggested by Quandt (1986), but also to the shape of the probability weighting functions. This is an intriguing alternative, since it can be shown in fact that the concavity of $H$ pulls towards risk-averse behavior for losses. Thus the favorite-longshot bias is compatible with risk-averse behavior, contrary to the standard interpretation.

Finally, let us return to explanation 4 of the favorite-longshot bias, based on the utility of gambling. First note that the method used by Jullien and Salanié is robust to a utility of gambling that may differ across races but is the same for all horses in a given race. Now assume that for horse $i$, there is a horse-specific utility of gambling $f\left(p_{i}, R_{i}\right)$, so that the value of this bet for a risk-neutral bettor is

$$
p_{i}\left(R_{i}+1\right)-1+f\left(p_{i}, R_{i}\right)
$$

By identifying this formula and the one above, we can see that our CPT estimates can be interpreted as representing the preferences of a risk-neutral bettor with a horse-specific utility of gambling given by

$$
f\left(p_{i}, R_{i}\right)=1-p_{i}-H\left(1-p_{i}\right)
$$


which only depends on the probability of a win. Moreover, we know that it is a decreasing function of $p_{i}$ for most horses. Thus this reinterpretation of Jullien and Salanié's CPT estimates brings us back to explanation 4 of Thaler and Ziemba (1988). There is in fact nothing in the data that allows the econometrician to distinguish between these two interpretations.

\section{Concluding Remarks}

This survey has attempted to describe the literature estimating and testing various utility representations on racetrack betting data. Clearly the literature is still in its infancy, and much more work is required before some definite conclusion emerges. We hope to have convinced the reader that this type of studies provides useful insights and is worth pursuing. In particular, the pattern that emerges is that the nature of the risk attitude that is imbedded in odds and winners data is more complex than predicted by a simple risk loving utility function, and may involve some elements of risk aversion as well. Assessing precisely which type of preference representation best fits the data would require more extensive studies. The methodology described here can apply to other existing theories, such as for instance regret theory (Loomes and Sugden (1982)) or disappointment theory (Gul (1991)).

As exposed in Kahneman, Slovic and Tversky (1982), departures from expected utility involve more "heuristics and biases" than the static discrepancy between "psychological" probabilities and objective probabilities that can be captured by a non-linear preference functional. The richness of the data available on horse races could help to test some of these other departures. This would require to collect more data than the odds and the winners, but there is for instance a potential to exploit information on the races, or the dynamics of odds. An attempt in this direction is Metzger (1985) who uses the ranking of the race during the day to provide some empirical supports for the gambler's fallacy (among others), here the effect of the outcome of the previous races on the perception of the respective winning probabilities of favorites and longshots. Ayton (1997) use data on UK football gambling and horse races to study the "support theory" developed by Tversky and Koehler (1994), with mitigated conclusions.

We have focused on horse races studies. Other gambles provide documented natural experiments. Because each gamble involves a different entertainement value and motivation of gamblers, it is difficult to compare the results obtained in different gambling contexts. Studies are still relatively scarce, and we will have to wait for more work before drawing any conclusion from the comparison of the patterns of behavior observed for various games. Still, let us mention that work has been conducted for lottery games, that sheds some light on the nature of cognitive biases. ${ }^{23}$ For instance it is well documented that the return varies with the numbers chosen (see Thaler and Ziemba (1988), Simon (1999)). Simon (1999) and Papachristou (2001) also examine whether lotto data exhibit

${ }^{23}$ For discussion of casino gambling see Eadington (1999). 
a gambler's fallacy pattern, with mixed conclusions. TV gambles have also been examined. References can be found in Beetsma and Schotman (2001) who estimate risk aversion for participants to the dutch TV show LINGO, or in Février and Linnemer (2002) who conclude from a study of the french Weakest Link that some pieces of information are not used by participants. ${ }^{24}$ Finally we should mention the recent work by Levitt (2002) using micro-data on gambling on National Football League to analyse biases and skills in individual betting.

\section{References}

Ali, M. (1977), "Probability and Utility Estimate for Racetrack Bettors", Journal of Political Economy, 85, 803-815.

Allais, M. (1953), "Le comportement de l'homme rationnel devant le risque : critique des postulats et axiomes de l'école américaine", Econometrica, 21, 503-546; english translation in The Expected Utility Hypothesis and the Allais Paradox, M. Allais and O. Hagen eds, Reidel (1979).

Arrow, K. (1964), "The Role of Securities in the Optimal Allocation of Risk Bearing", Review of Economic Studies, 31,91-96.

Asch, P., Malkiel, B. and R. Quandt (1982), "Racetrack Betting and Informed Behavior", Journal of Financial Economics, 10, 187-194.

Ayton, P. (1997), "How to bBe Incoherent and Seductive: Bookmakers' Odds and Support Theory", Organizational Behavior and Human Decision Processes, 72-1, .99-115.

Beetsma, R. and P. Schotman (2001), "Measuring Risk Attitude in a Natural Experiments: Data from the Television Game Show LINGO", The Economic Journal, 111, 821-848.

Bradley, I. (2003), "Preferences of a Representative Bettor", Economoc Letters, 409-413.

Bushe, K. and C.D. Hall (1988), "An Exception to the Risk Preference Anomaly", Journal of Business, 61, 337-346.

Camerer, C. (1995), "Individual Decision Making", in The Handbook of Experimental Economics, J. Kagel and A. Roth eds, Princeton University Press.

Craft, N.F.R. (1985), "Some Evidence of Insider Tarding in Horse Race Betting in Britain", Economica, 52, 295-304.

Donkers, B., Melenberg, B. and A. Van Soest (2001), "Estimating Risk Attitude using Lotteries: A Large Sample Approach", The Journal of Risk and Uncertainty, 22, 165-165.

Eadington, W.R. (1999), "The Economics of Casino Gambling", Journal of Economic Perspectives, 13-3, 173-192.

Février, P. and L. Linnemer (2002), "Strengths of the Weakest Link"?, mimeo, CREST.

Friedman, M. and L. Savage (1948), "The Utility Analysis of Choices Involving Risk", Journal of Political Economy , 56, 279-304.

${ }^{24}$ Levitt (2003) also use the Weakest Link to test for discriminatory behaviour. 
Golec, J. and M. Tamarkin (1998), "Bettors Love Skewness, Not Risk, at the Horse Track", Journal of Political Economy, 106-1, 205-225.

Griffith, R. (1949), "Odds Adjustment by American Horses Race Bettors", American Journal of Psychology, 62, 290-294. Reprinted in Hausch, Lo and Ziemba (1994).

Guiso, L, Haliassos, M. and T. Jappelli (2002), Household Porfolios, MIT Press.

Gul, F. (1991), "A Theory of Disappointment Aversion", Econometrica, $59,667-86$.

Hausch, D., Lo, V. and W. Ziemba (1994), "Pricing Exotic Racetrack Wagers", in Hausch, Lo and Ziemba eds (1994), Efficiency of Racetrack Betting Markets, Academic Press.

Hausch, D., Lo, V. and W. Ziemba (1994), Efficiency of Racetrack Betting Markets, Academic Press.

Henery, R. (1985), "On the Average Probability of Losing Bets on Horses with Given starting Price Odds", Journal of the Royal Statistical Society, Series A, 148, 342-349.

Jullien, B. and B. Salanié (2000), "Estimating Preferences under Risk: The Case of Racetrack Bettors", Journal of Political Economy, 108, 503-530.

Kahneman, D. and A. Tversky (1979), "Prospect Theory: An Analysis of Decision under Risk", Econometrica, 47, 263-291.

Kahneman, D., P. Slovic and A. Tversky (1982), Judgement Under Uncertainty: Heuristics and Biases, Cambridge University Press.

Kanto A.J., Rosenqvist G. and Suvas A. (1992), "On Utility Function Estimation of Racetrack Bettors", Journal of Economic Psychology, 13, 491498.

Levitt, S.D. (2002), "How Do Market Function? An Empirical Analyis of Gambling on the National Football League", NBER Working Paper 9422, National Bureau of Economic Research.

Levitt, S.D. (2003), "Testing Theories of Discrtimination: Evidenvce from the "Weakest Link" , NBER Working Paper 9449, National Bureau of Economic Research.

Loomes, G. and R. Sugden (1982), "Regret Theory: An Alternative Theory of Rational Choice under Uncertainty", em Economic Journal, 92, 805824 .

Machina, M. (1982), "Expected Utility' Analysis Without the Independence Axiom", Econometrica , 50, 277-323.

Markowitz, H. (1652), "The Utility of Wealth", Journal of Political Economy, 60, 151-158.

McGlothlin, W. (1956), "Stability of Choices Among Uncertain Alternatives", American Economic Review, 69, 604-615.

Metzger, M.A. (1985), "Biases in Betting: An Application of Laboratory Findings", in Hausch, Lo and Ziemba eds (1994), Efficiency of Racetrack Betting Markets, Academic Press.

Papachristou, G. (2001), "The British Gambler's Fallacy", mimeo, Aristotle University of Thessaloniki. 
Prelec, D. (1998), "The Probability Weighting Function", Econometrica, 66, 497-527.

Quandt, R. (1986), "Betting and Equilibrium", Quarterly Journal of Economics, 101, 201-207.

Sauer, R.D. (1998), "The Economics of Wagering Markets", Journal of Economic Literature, XXXVI, 2021-2064.

Shin, H. S. (1991), "Optimal Odds Against Insider Traders", Economic Journal, 101, 1179-1185.

Shin, H. S. (1992), "Prices of State-Contingent Claims with Insider Traders, and the Favorite-Longshot Bias", Economic Journal, 102, 426-435. Reprinted in Hausch, Lo and Ziemba (1994).

Shin, H. S. (1993), "Measuring the Incidence of Insider Trading in a Market for State-Contingent Claims", Economic Journal, 103, 1141-1153.

Simon, J. (1999), "An Analysis of the Distribution of Combinations Chosen by UK National Lottery Players", Journal of Risk and Uncertainty, 17, 243-276.

Thaler, R. and W. Ziemba (1988), "Anomalies - Parimutuel Betting Markets: Racetracks and Lotteries", Journal of Economic Perspectives, 2, 161174 .

Tversky, A. and D. Kahneman (1992), "Advances in Prospect Theory: Cumulative Representation of Uncertainty", Journal of Risk and Uncertainty, 5, 297-323.

Tversky, A. and D. Koehler (1994), "Support Theory: A non-extensional representation of subjective probabilities", Psychological Review, 101, 547-567.

Weitzman, M. (1965), "Utility Analysis and Group Behavior: An Empirical Study", Journal of Political Economy, 73, 18-26. 